\title{
Principais características demográficas e nosológicas das doenças da cavidade oral de cães atendidos em um serviço de odontologia veterinária*
}

\section{Main demographic and nosological characteristics of diseases of the oral cavity of dogs treated at a veterinary dentistry service}

\author{
Brenda Auad Martins Pinto, ${ }^{* *}$ Andrei Ferreira Nicolau da Costa, ${ }^{* *}$ Claudia Coelho Youle, ${ }^{* *}$ \\ Mário dos Santos Filho, ${ }^{* * *}$ Eduardo Butturini de Carvalho***
}

\section{Resumo}

Afecções da cavidade oral como o cálculo dentário (CD) e a doença periodontal (DP) são frequentes na clínica de cães e têm grande impacto na saúde e qualidade de vida dos pacientes acometidos. No entanto, a adoção de medidas preventivas ainda é difícil, uma vez que a frequência das doenças da cavidade oral em cães ainda é pouco compreendida no Brasil. O objetivo deste estudo foi avaliar características demográficas e nosológicas, como os hábitos alimentares e de manejo de escovação, dos distúrbios da cavidade oral de 198 cães atendidos no período compreendido entre 2013 e 2019, em um serviço de odontologia veterinária, na cidade do Rio de Janeiro. A maioria dos cães atendidos não tinha raça definida. Entre os de raça pura, Yorkshire Terrie foi a mais prevalente, não havendo distinção significativa entre o gênero, em todos os casos. Quanto à idade, observou-se uma predominância de animais de meia idade a idosos, com faixa etária acima dos sete anos. Dentre as afecções mais prevalentes, o destaque se deve ao cálculo dentário e à doença periodontal, seguidos por gengivite e halitose. Quanto aos hábitos dos tutores, notou-se baixa adesão à realização de escovação rotineira, e um alto percentual no fornecimento de petiscos. Avaliando-se os resultados e relacionando-os aos hábitos alimentares dos pacientes, surge a hipótese de que a alimentação à base de ração comercial, de alguma forma possa contribuir para evolução do cálculo dentário, necessitando estudos com maior amostragem para elucidação.

Palavras-chave: Cálculo dentário, doenças periodontais, hábito alimentar, medicina preventiva.

\begin{abstract}
Diseases of the oral cavity, such as Dental Calculus (DC) and Periodontal Disease (PD), are frequent in the dog clinic and have a great impact on the health and quality of life of affected patients. However, the adoption of preventive measures is still difficult, since the epidemiology of diseases of the oral cavity is still poorly understood in Brazil. The aim of this study was to evaluate demographic and nosological aspects - such as feeding and brushing habits - of disorders of the oral cavity of 198 dogs treated in the period between 2013 and 2019, in a veterinary dentistry service, in the city of Rio de Janeiro. The most prevalent breeds were mixed breed dogs, followed by Yorkshire Terries, with no significant distinction between the gender. As for age, there was a predominance of animals from middle age to the elderly, with ages above seven years old. Among the most prevalent conditions, the highlight is due to dental calculus and periodontal disease followed by gingivitis and halitosis. Regarding the tutors' habits, there was a low level of routine brushing, and a high percentage in the supply of snacks. Evaluating the results and relating them to the eating habits of the patients, the hypothesis that comercial dog food feeding may somehow contribute to dental calculus evolution, urging studies with bigger samples for a deeper investigation.
\end{abstract}

Keywords: Dental calculus, periodontal diseases, eating habits, preventive medicine.

\section{Introdução}

A frequência das afecções da cavidade oral em cães, como cálculo dentário (CD) e doença periodontal (DP) é pouco estudada no Brasil. Sabe-se que são frequentes na clínica de cães e têm grande impacto na saúde e na qualidade de vida dos animais. Além de comprometerem o convívio tutor-pet, também podem predispor às doenças sistêmicas graves como endocardite bacteriana, nefropatias, hepatopatias e síndromes de resposta inflamatória sistêmica (Semedo-Lemsaddek et al., 2016; Kouki et al., 2013; DeBowes et al., 1996).

Aproximadamente $40 \%$ dos cães com idade entre 1 e 4 anos e $89,4 \%$ dos cães entre 12 e 13 anos de idade avaliados em um estudo na República Tcheca apresentaram DP, independentemente de raça ou de sexo, o que demonstra a importância e alta prevalência dessa doença (Kyllar \& Witter, 2005).

\footnotetext{
${ }^{*}$ Recebido em 3 de setembro de 2020 e aceito em 2 de novembro de 2020.

** Médica Veterinária Autônoma, Rio de Janeiro, RJ, Brasil.

***Universidade de Vassouras, Curso de Medicina Veterinária, Vassouras, RJ, Brasil.

Autor para correspondência: EduardoButturini@hotmail.com
} 
A placa bacteriana - biofilme composto pelos agentes etiológicos primários da doença periodontal - é definida como um material pegajoso, amarelado que se forma sobre o esmalte dentário (Gioso, 2007) e induz um processo inflamatório na gengiva reversível em caso de remoção do agente irritante. Quando a placa bacteriana não é removida e a gengivite se instala, pode progredir para a periodontite, afetando estruturas como o ligamento periodontal e o osso alveolar (Telhado et al., 2004; Inaba \& Amano, 2010; Niemiec, 2008; Okui et al., 2015).

Apesar da grande relevância do componente microbiológico, a etiologia da DP relaciona-se a fatores do hospedeiro (comportamentais, sistêmicos e até mesmo genéticos e ambientais) que determinarão o grau de evolução e do curso natural da doença se não prevenida ou tratada (Inaba \& Amano, 2010; Van Dyke \& Dave, 2005).

Evidências apontam que a escovação dentária pode auxiliar na prevenção da DP (Roudebush et al., 2005). Uma vez instalada, o tratamento da DP e das infecções odontogênicas fundamenta-se na remoção da placa bacteriana supra e subgengival, polimento das coroas dentárias e antibioticoterapia (Salinas et al., 2006; Willard, 2015). Conhecer a epidemiologia pode ter um importante papel no diagnóstico precoce e na prevenção dessas afecções. Destarte, o objetivo deste estudo é investigar os aspectos epidemiológicos de cães atendidos por um serviço de odontologia veterinária na cidade do Rio de Janeiro, no período compreendido entre 2013 e 2019.

\section{Material e métodos}

Foram analisadas as fichas clínicas no sistema informatizado de um serviço especializado de odontologia veterinária (operado por uma médica veterinária com especialização na referida área $e$ experiência de atendimento especializado de 20 anos) pertencente a um hospital veterinário situado no bairro de Laranjeiras, na cidade do Rio de JaneiroRJ, no período de 2013 até 2019. Os casos eram referenciados ora pelos setores de clínica geral e outras especialidades do próprio hospital, ora por outras clínicas e consultórios. Ressalta-se ainda, como relatado pela profissional responsável, que muitos tutores procuram o serviço por conta própria - sem a indicação de um médico veterinário. Como critério de inclusão, foram coletados dados apenas de fichas clínicas de pacientes caninos contendo no mínimo os seguintes dados: raça, sexo, data de nascimento, suspeita clínica e achados do exame físico odontológico. Após a análise de 2.379 fichas, apenas 198 cães foram incluídos no estudo. As informações coletadas foram: idade, sexo, raça, alimentação, hábitos de escovação, presença de cálculo dentário, gengivite, halitose, presença e grau de DP, fraturas dentárias, retenção de dente decíduo e dados clínicos acerca de cardiopatias, nefropatias, e exames complementares como leucometria global, fosfatase alcalina e creatinina sérica. Considerou-se leucocitose, leucometria global acima de $16.000 / \mu \mathrm{L}$, leucopenia, leucometria global abaixo de $8.000 / \mu \mathrm{L}$ e anemia, um volume globular inferior a $40 \%$.
Com base nesses registros clínicos, foi realizada, por meio de software próprio(GraphPad Prism v6.0®), estatística descritiva (média, desvio-padrão, frequências absoluta e relativa), correlação de Pearson (entre grau de DP e idade) e teste de Fisher para comparar a presença de CD ou DP entre cães alimentados exclusivamente com ração ou com algum tipo de alimentação natural e entre cães que recebem ou não algum tipo de escovação dentária.

\section{Resultados}

Após a triagem inicial das fichas clínicas, apenas 198 cães foram selecionados para a amostra do estudo. A média de idade dos animais atendidos foi de $108 \pm 50$ meses, sendo $46,5 \%$ fêmeas e $53,5 \%$ machos. Quase um terço $(27,2 \%)$ dos animais eram cães sem raça definida e as raças mais atendidas foram Yorkshire, Dachshund, Poodle e Shih-tzu. Os dados demográficos da população estudada estão resumidos na Tabela 1.

Tabela 1: Dados demográficos dos cães atendidos pelo setor de odontologia de uma clínica veterinária da cidade do Rio de Janeiro

\begin{tabular}{ll}
\hline Dados demográficos dos cães atendidos pelo setor de odontologia \\
\hline Total de animais $(\mathrm{n})$ & $\mathrm{n}=198$ \\
\hline Média de idade & $107,98 \pm 49,62$ meses \\
\hline Raças & Sem raça definida (SRD) $-53 / 198(27,2 \%)$ \\
& Yorkshire $-27 / 198(13,6 \%)$ \\
& Dachshund $-14 / 198(7,1 \%)$ \\
& Poodle $-11 / 198(5,9 \%)$ \\
& Shih-tzu $-11 / 198(5,9 \%)$ \\
& Maltês $-8 / 198(4,1 \%)$ \\
& Chihuahua $-7 / 198(3,6 \%)$ \\
& Outras* $-67 / 198(32,6 \%)$
\end{tabular}

* - Bichon Frise, Boston Terrier, Boxer, Buldogue inglês, Buldogue Francês, Chihuahua, Chow Chow, Cocker Spaniel,Cotton de Toulear, Fox Paulistinha, Fox Terrier, Galgo taliano, Golden Retriever, Jack Russel Terrier, Labrador, Lhasa Apso, Lulu da Miniatura, Scottish Terrier, Staffordshire, West Highland White Terrier e Whippet.

Sexo Fêmeas - 92/198 (46,5\%)

Machos - 106/198 (53,5\%)

Ao exame clínico, $48 \%$ dos cães apresentaram CD, 33,3\% gengivite e $17,2 \%$ halitose. Entre cães com mais de 4 anos, $61,7 \%$ apresentavam DP. As raças mais afetadas por DP ou CD foram: Yorkshire (16,1\%), Dachshund $(7,7 \%)$ e Poodle $(7 \%)$. A informação sobre o grau de DP estava presente em apenas 27 fichas clínicas e a média entre essas foi $3,2 \pm 1,2$ (usando a escala de 1 a 4$)$. Houve fraca correlação positiva $(0,385$, correlação de Pearson, $p=0,047$ ) entre idade e grau de DP. Fraturas dentárias totalizaram $5,1 \%$ dos casos (dentes mais afetados: cinco caninos superiores e dois inferiores, cinco quartos pré-molares - quatro superiores e um inferior, dois incisivos (um superior e um inferior) e um molar inferior. Apenas dois casos de maloclusão (1\%) foram atendidos. Entre cães de até 24 meses, 28,6\% apresentaram retenção de dente decíduo. Os achados clínicos nos 198 animais examinados estão resumidos na tabela 2 . 
Tabela 2: Prevalência dos achados clínicos nas consultas odontológicas analisadas

\begin{tabular}{lc}
\hline Prevalência dos achados clínicos nas consultas odontológicas (n=198) \\
\hline Cálculo dentário & $95 / 198(48,0 \%)$ \\
Cálculo dentário ou doença periodontal & $125 / 198(63,1 \%)$ \\
Comunicação oronasal & $2 / 198(1 \%)$ \\
Gengivite & $66 / 198(33,3 \%)$ \\
Halitose & $34 / 198(17,2 \%)$ \\
Fístulas oronasais & $2 / 198(1 \%)$ \\
Fraturas dentárias & $10 / 198(5,1 \%)$ \\
Linfadenomegalia em linfonodos de cabeça & $3 / 198(1,5 \%)$ \\
Maloclusão & $2 / 198(1 \%)$ \\
\hline
\end{tabular}

Dentre os cães com alguma cardiopatia (9\%), 81,2\% apresentavam CD ou DP. Entre os 7,9\% de cães com creatinina acima de 1,4mg/dL, 70\% tinham CD e 50\% gengivite. Cães alimentados com ração apresentaram mais CD ou DP que os com algum tipo de alimentação natural na dieta $(p<0,05)$.

Cães que receberam escovação dentária no mínimo semanalmente não apresentaram menos CD ou DP que os que não recebem escovação ( $80,8 \%$ vs.77,9\%, $p=0,753)$. Outros achados sobre hábitos dos tutores relacionados à saúde oral dos seus cães estão apresentados na tabela 3 .

Tabela 3: Hábitos dos tutores associados à saúde oral dos cães

Hábitos dos tutores associados à saúde oral dos cães

\begin{tabular}{ll}
\hline Alimentação & Natural - 12,6\% (20/159) \\
& Ração - 74,2\% (118/159) \\
& Misto (ração/natural) - 13,2\% $(21 / 159)$ \\
\hline Escovação & Não realiza escovação nunca - 86\% (170/198) \\
& Ao menos uma vez por semana - 14\% (28/198) \\
& Frequência média - 2,6 $\pm 2,5$ vezes/semana \\
\hline Uso de brinquedos & Relataram que o cão dispõe de brinquedos $-3,5 \%(7 / 198)$ \\
\hline Petiscos & Recebem frequentemente algum tipo de petisco - 76,4\% (55/72) \\
& Tipos de petiscos: \\
& Biscoito - 31,5\%; \\
& Frutas - 29,6\%; \\
& Ossos - 13\% \\
& Biscoito específico para prevenção de doenças orais $-9,2 \%$
\end{tabular}

Foi observada leucocitose em $13,2 \%$ dos cães (17/129), leucopenia em $21,7 \%$ (28/129) e anemia em 16,4\% (21/128) dos adultos. Em amostra de 23 cães (com exames complementares e descrição do grau de DP), não foi observada correlação significativa entre o grau de doença periodontal e: leucometria global $(p=0,893)$, fosfatase alcalina $(p=0,178)$ e creatinina séricas $(p=0,169)$.

\section{Discussão}

Após a triagem inicial de 2.379 fichas de atendimentos odontológicos de cães e gatos (2013 a 2019, com média de 28,3 atendimentos por mês), apenas 198 cães foram incluídos no estudo. A baixa porcentagem de cães incluídos deveu-se a um grande número de fichas clínicas descrevendo a realização de procedimentos cirúrgicos, visitas para coleta de exames pré-operatórios, consultas de revisão pós-operatória, atendimentos de felinos e fichas com informações incompletas. Esta última condição - fichas com informações incompletas - sugere a necessidade de uma padronização no preenchimento dos prontuários.

Com o avanço da idade do cão pode ocorrer aumento na frequência e a gravidade do acúmulo de cálculo dentário e por consequência a periodontite (Telhado et al., 2004). Neste estudo, o perfil etário dos animais consultados, 108 \pm 50 meses, pode indicar que há maior procura dos serviços de odontologia em razão de afecções orais em animais com mais idade.

A literatura relata que não há diferença na prevalência da periodontite em cães quanto ao sexo do animal, o que também foi observado nesse estudo (Carreira et al., 2015).

Estudos epidemiológicos indicaram que a doença periodontal ocorre mais em raças pequenas e raças miniaturas (Gioso, 2007; Harvey et al., 1994). Neste estudo, foi verificada uma maior prevalência de raças pequenas e miniaturas, como Yorkshire, Daschund, Poodle e Shitzu, todavia este aspecto pode representar apenas um viés de amostragem, tendo em vista que a clínica se localiza em área urbana, onde há predominância cães desse porte.

O acúmulo de placa bacteriana e CD em um cão de pequeno porte pode ser agravado por características inerentes à sua anatomia, como um suporte ósseo mais frágil e apinhamento dentário decorrente de espaços interdentários reduzidos. Esse perfil morfológico pode reduzir a eficácia de processos mecânicos naturais de remoção de sujidades, como mastigação e ato de roer (Santos et al., 2012 e ).

A raça Yorkshire Terrier apresentou grande prevalência neste estudo. A prolongada permanência da dentição decídua nessa raça pode ocasionar imperfeição no alinhamento e orientação da dentição permanente (Pibot, 2007). Neste estudo, 28,6\% dos animais até 24 meses apresentaram retenção de dentes decíduos. Esse achado é importante para ressaltar a importância do exame da cavidade oral em todas as faixas etárias, devendo fazer parte do exame clínico geral. Observou-se alta prevalência de afecções da cavidade oral em cães com nefropatia ou cardiopatia, o que pode predispor o cão a complicações como 
glomerulopatias e endocardite bacteriana. A pielonefrite e a nefrite intersticial podem estar relacionadas com a bacteremia que por sua vez está relacionada com a infeção oral em cães. A doença renal imunomediada, particularmente a glomerulonefrite, também pode ser uma consequência do grau crônico da bacteremia e toxemia associadas a DP (DeBowes, et al., 1996). Estudos comprovam que a terapia periodontal melhora a taxa de filtração glomerular tanto em animais saudáveis, como em doentes renais (Artese et al., 2010; Graziani et al., 2010).

Mais de $80 \%$ dos animais com alguma cardiopatia apresentaram CD ou DP, Estudos demostraram que a DP está associada a um aumento na incidência de alterações a nível da válvula atrioventricular (Glickman et al., 2009; Pavlica et al., 2008), podendo se associar a endocardite bacteriana por Enterococcus spp. (Semedo-Lemsaddek et al., 2016). Estas alterações podem estar relacionadas com o processo senil desencadeado pelos animais, e não necessariamente relacionadas às doenças em questão.

É necessária a formação de placa bacteriana na cavidade oral que conduz à inflamação das estruturas de suporte dos dentes, tendo seu curso de progressão natural desde periodontite leve à grave, atingindo o ligamento periodontal e osso alveolar. Nessa fase, as bactérias podem disseminar para outros órgãos via corrente sanguínea, de forma a causar doenças sistêmicas, incluindo endocardite infecciosa (Semedo-Lemsaddek et al., 2016).

As bactérias são os agentes infecciosos mais comuns causadores de endocardite em cães e gatos e acometem principalmente o tecido valvar (Kittleson \& Kienle, 1998). Quando as bactérias colonizam uma valva cardíaca, geralmente causam lesões proliferativas as quais podem levar a coaptação inadequada da valva, resultando em regurgitação sanguínea ou em estenose do orifício valvar. A endocardite associada à doença periodontal pode ocorrer em qualquer sexo, raça e principalmente em cães mais velhos (Peddle \& Sleeper, 2007).

Tutores de cães devem sempre ser aconselhados a adotar medidas profiláticas de saúde oral dos seus animais, atuando de forma proativa para prevenir complicações sistêmicas (SemedoLemsaddek et al., 2016). A escovação dentária é o método mais eficaz para interromper a formação do agente etiológico da periodontite, porém, depende da colaboração do animal e seu tutor. No entanto, para ser eficiente precisa ser realizada no

\section{Referências}

ARTESE, H.P.C.; SOUSA, C.O.D.; LUIZ, R.R.; SANSONE, C.; TORRES, M.C.M.D. B. Effect of non-surgical periodontal treatment on chronic kidney disease patients. Brazilian oral research, v.24, n.4, p. 449-454, 2010.

BROWN, W.Y.; McGENITY, P. Effective periodontal disease control using dental hygiene chews. Journal of veterinary dentistry, v. 22, n.1, p.16-19, 2005.

CARREIRA, L.M.; DIAS, D.; AZEVEDO, P. Relationship between gender, age, and weight and the serum ionized calcium variations in dog periodontal disease evolution. Topics in companion animal medicine, v. 30, n.2, p. 51-56, 2015.

DeBOWES, L.J.; MOSIER, D.; LOGAN, E.; HARVEY, C.E.; LOWRY, S.; RICHARDSON, D.C. Association of periodontal disease and histologic lesions in multiple organs from 45 dogs. Journal of veterinary dentistry, v. 13, n. 2, p.57-60, 1996. mínimo três vezes por semana (Watanabe et al., 2015; Brown \& McGenity, 2005), removendo mecanicamente constituintes da placa bacteriana que se desenvolvem de 1 a 2 dias. Após este período, a placa bacteriana pode causar inflamação no periodonto e nos tecidos moles adjacentes. (Gioso, 2007; Brown \& McGenity, 2005; Wiggs \& Lobprise, 1997)

Neste estudo, não houve diferença estatisticamente significativa na prevalência de DP e CD entre cães que recebem escovação no mínimo semanalmente e os que não recebem. É possível que isso se deva ao fato de a escovação ter de ser feita com maior frequência que ao menos uma vez por semana e que a escovação não tenha sido realizada da maneira correta. Outra possibilidade é que os tutores não tenham relatado de forma fidedigna a frequência de escovação. Alimentação com ração seca pode facilitar a formação de CD e DP por alterar a microbiota oral (Roudebush et al., 2005). Neste estudo, a presença de alimentação natural na dieta associou-se a menor prevalência de DP e CD.

\section{Conclusões}

Conclui-se que CD, DP, gengivite e halitose são afecções da cavidade oral são bastante prevalentes em cães atendidos por um setor especializado de odontologia, sendo as raças de pequeno porte as mais afetadas e não havendo diferença entre os sexos. Grande parte dos animais com alguma cardiopatia ou nefropatia apresentaram afecções da cavidade oral que podem causar complicações sistêmicas, como endocardite e glomerulopatia bacteriana. Isso demonstra a atenção especial que se deve ter com a saúde oral desses indivíduos.

O exame da cavidade oral deve ser recomendado em todos os cães em todas as idades, já que quase $29 \%$ dos animais até 24 meses apresentaram retenção de dente decíduo e mais de $60 \%$ dos cães acima de quatro anos apresentaram doença periodontal.

Apesar de a escovação não ter se associado a menor prevalência de DP, há fortes evidências na literatura que essa prática tem importante papel na profilaxia e deve ser estimulada nos tutores. Por fim, conclui-se que estudos com maiores populações e com mais dados são importantes para o entendimento da epidemiologia dessas doenças em cães.

GIOSO, M.A. Odontologia veterinária para o clínico de pequenos animais. São Paulo: Manole, 2. ed., 2007. 147p.

GLICKMAN, L.T.; GLICKMAN, N.W.; MOORE, G.E.; GOLDSTEIN, G.S.; LEWIS, H.B. Evaluation of the risk of endocarditis and other cardiovascular events on the basis of the severity of periodontal disease in dogs. Journal of the American Veterinary Medical Association, v. 234, n. 4, p.486-494, 2009.

GRAZIANI, F.; CEI, S.; LaFERLA, F.; VANO, M,; GABRIELE, M.; TONETTI, M. Effects of non-surgical periodontal therapy on the glomerular filtration rate of the kidney: an exploratory trial. Journal of clinical periodontology, p. 37, n. 7, p. 638-643, 2010.

HARVEY, C.; SHOFER, F.; LASTER, L. Association of age and body weight with periodontal disease in North American dogs. Journal of veterinary dentistry, v.11, n.3, p. 94-105, 1994.

INABA, H.; AMANO, A. Roles of oral bacteria in cardiovascular diseases from molecular mechanisms to clinical cases: Implication of periodontal diseases in development of systemic diseases. Journal of pharmacological sciences, v. 113, n. 2, p.103-109, 2010. 
KITTLESON, M.D.; KIENLE, R.D. Small animal cardiovascular medicine. Maryland Heights: Mosby, 1ed, 1998. 603p.

KOUKI, M.; PAPADIMITRIOU, S.; KAZAKOS, G.; SAVAS, I.; BITCHAVA, D. Periodontal disease as a potential factor for systemic inflammatory response in the dog. Journal of veterinary dentistry, v. 30, n. 1, p. 26-29, 2013.

KYLLAR, M.; WITTER, K. Prevalence of dental disorders in pet dogs. Veterinární Medicina, v.50, n.11, p.496-505, 2005.

NIEMIEC, B.A. Periodontal disease. Topics in companion animal medicine, v. 23, n. 2, p.72-80, 2008.

OKUI, A.; SOGA, Y.; KOKEGUCHI, S.; NOSE, M.; YAMANAKA, R.; KUSANO, N.; et al. Detection of identical isolates of Enterococcus faecalis from the blood and oral mucosa in a patient with Infective Endocarditis. Internal Medicine, v. 54, n. 14, p.18091814, 2015.

PAVLICA, Z.; PETELIN, M.; JUNTES, P.; ERZEN, D.; CROSSLEY, D.A.; SKALERIC, U. Periodontal disease burden and pathological changes in organs of dogs. Journal of veterinary dentistry, v. 25, n. 2, p.97-105, 2008.

PIBOT, D.V.M.P. Raça: um parâmetro fundamental em nutrição clínica. Veterinary Focus, v. 17, n. 2, 2007. 41p.

ROUDEBUSH, P.; Logan, E.; Hale, F.A. Evidence-Based Veterinary Dentistry: A Systematic Review of Homecare for Prevention of Periodontal Disease in Dogs and Cats. Journal of Veterinary Dentistry, v. 22, n. 1, p.6-15, 2005.

SALINAS, M.B.; RIU, N.C.; AYTÉS, L.B.; ESCODA, C.G. Susceptibilidad antibiótica de las bacterias causantes de infecciones odontogénicas. Medicina Oral, Patología Oral y Cirugía Bucal (Internet), v. 11, n. 1, p.70-75, 2006.
PEDDLE, G.; SLEEPER, M.M. Canine bacterial endocarditis: a review. Journal of the American Animal Hospital Association, v. 43, n. 5, p.258-263, 2007.

SANTOS, N.S.D.; CARLOS, R.S.A.; ALBUQUERQUE, G.R. Doença periodontal em cães e gatos-revisão de literatura. Medvep-Rev ista Científica de Medicina Veterinária, v. 10, n. 32 p.30-41, 2012.

SEMEDO-LEMSADDEK, T.; TAVARES, M.; SÃO BRAZ, B.; TAVARES, L.; OLIVEIRA, M. Enterococcal infective endocarditis following periodontal disease in dogs. PloS one, v. 11, n. 1 , e0146860, 2016.

TELHADO, J.; JUNIOR, A.M.; DIELE, C.A.; MARINHO, M.S. Incidência de cálculo dentário e doença periodontal em cães da raça pastor alemão. Ciência Animal Brasileira, v. 5, n. 2, p.99-104, 2004.

VAN DYKE, T.E.; DAVE, S. Risk factors for periodontitis. Journal of the International Academy of Periodontology, v. 7, n. 1, p.3-5, 2005.

WATANABE, K.; HAYASHI, K.; KIJIMA, S.; NONAKA, C.; YAMAZOE, K. Tooth brushing inhibits oral bacteria in dogs. Journal of Veterinary Medical Science, v. 77, n. 10, p.1323-1325, 2015.

WIGGS, R.B.; LOBPRISE, H.B. Veterinary dentistry: principles and practice. Lippincott: Wiley-Blackwell, 1997. 748p.

WILLARD, M.D. Desordens da Cavidade Oral, Faringe e Esôfago. In.: NELSON, R.W.; COUTO, C.G. Eds. Medicina Interna de Pequenos Animais. Rio de Janeiro: Elsevier. 5.ed. p.428-439, 2015. 